\title{
NÃOTECIDO ELETROFIADO COM ATIVIDADE ANTI- HEMORRÁGICA PARA TRATAMENTO DE EPISTAXE
}

\author{
G. Maestri ${ }^{1}$, R. L. Boemo ${ }^{2}$, A. A. U. de Souza ${ }^{3}$ e A. P. S. Immich ${ }^{1}$ \\ ${ }^{1}$ Universidade Federal de Santa Catarina, Campus de Blumenau, curso de Engenharia Têxtil, \\ Blumenau-SC \\ ${ }^{2}$ Universidade Federal de Santa Catarina, Hospital Universitário, Departamento de cirurgia, \\ Serviço de Otorrinolaringologia e Fonoaudiologia, Florianópolis - SC \\ ${ }^{3}$ Universidade Federal de Santa Catarina, departamento de Engenharia Química e Engenharia \\ de Alimentos, Florianópolis - SC \\ E-mail para contato: gabriela.maestri@grad.ufsc.br
}

\begin{abstract}
RESUMO - Epistaxe é a perda de sangue pela fossa nasal originada pela ruptura de veias da mucosa do nariz. Dentre os procedimentos utilizados para tratar a epistaxe estão: cauterização, tamponamento com gase e esponjas lubrificadas, aplicação de esteroides nasais (spray), etc. Porém, o simples tamponamento nem sempre é eficaz e a cauterização pode ser prejudicada pela dificuldade de encontrar o ponto de origem do sangramento durante a epistaxe, além de causar grande desconforto ao paciente. Dessa forma, o objetivo deste estudo é propor uma alternativa rápida para tratar casos de epistaxe, que promova o mínimo de efeito colateral e lesão ao paciente. Assim, para controlar a epistaxe, propõe-se um tampão produzido de um tecido nãotecido eletrofiado de Poli(L-ácido láctico) funcionalizado com um agente anti-hemorrágico (ácido tranexâmico) que deverá ser utilizado para tamponar a fossa nasal durante epistaxe. Para a produção do nãotecido foi utilizada a técnica de eletrofiação,cujos parâmetros como vazão de alimentação do polímero, voltagem aplicada e distância entre agulha e coletor foram otimizados para o polímero estudado.. Os nãotecidos produzidos foram analisados por microscopia eletrônica de varredura e os resultados mostram a uniformidade das fibras produzidas, com baixa porosidade e regularidade de diâmetros. Com este dispositivo, pretende-se facilitar a o tratamento de epistaxe sem a necessidade de uma intervenção cirúrgica.
\end{abstract}

\section{INTRODUÇÃO}

Epistaxe, uma das principais urgências na otorrinolaringologia, é a perda de sangue pela fossa nasal oriunda do rompimento de veias da mucosa do nariz, conforme Anikko (2010). Com base em Faistauer (2009), episódios de epistaxe acontecem geralmente em crianças maiores de 2 anos, e em idosos com idades entre 70 a 79 anos, e tem ocorrência de aproximadamente 30 pessoas para cada 100.000 habitantes.

A epistaxe é classificada clinicamente em dois tipos: anterior e posterior. A maioria dos casos ocorre do tipo anterior, apresentando sangramento moderado, enquanto a epistaxe do tipo posterior é mais grave e na maioria das vezes necessita de medidas mais severas. 
Balbani (1999) mostra que as causas da epistaxe podem ser divididas em local e sistêmica. As causas locais mais frequentes são traumas e problemas inflamatórios da mucosa nasal, tumores e cirurgias endonasais. Causas sistêmicas podem ser discrasias sanguíneas, anormalidades plaquetárias, malformações vasculares, anticoagulação, uso de corticóides nasais e fatores diversos como desnutrição e infecções. Estima-se que $60 \%$ da população adulta já tenham sofrido ao menos uma vez com este sangramento. A doença de telangectasia hemorrágica hereditária, também conhecida como doença de Osler-Rendu-Weber, vale ser mencionada uma vez que é uma das principais doenças vasculares que causam epistaxe intermitente.

Os procedimentos mais utilizados para tratar a epistaxe são cauterização, tamponamento com gase e esponjas lubrificadas, aplicação de esteroides nasais (spray), celulose oxidada, uso do oximetazolina (Afrin), que atua aliviando a obstrução nasal e facilitando o fluxo de ar, entre outros.

A cauterização química é realizada sob anestesia, inserindo um algodão embebido em anestésico na fossa nasal por alguns minutos até que a anestesia e vasoconstricção local sejam alcançadas. Após a retirada do algodão, o ponto onde o sangue está saindo é tocado com pérola de nitrato de prata por alguns segundos. Os dois lados do septo jamais devem ser cauterizados em pontos iguais, pois corre o risco de perfuração septal. A cauterização elétrica é indicada quando não se consegue estancar o sangue com a cauterização química. Esta é mais violenta e favorável à exposição de cartilagem e/ou perfuração septal, de acordo com Meirelles (2012).

Tamponamentos nasais em geral, são utilizados quando o sangramento não é muito severo, ou em casos de cauterização em que o médico otorrinolaringologista não consegue identificar a saída exata do sangramento. Existem vários materiais que podem ser usados no tamponamento nasal: dedo de luva, preservativo com esponja, algodão embebido, gaze com vaselina, etc. Entretanto, pode gerar dificuldades ao paciente, tais como reflexo vagal, epífora, rinossinusites, e Síndrome do Choque Tóxico.

A partir do que mostram estudos de Balbani (1999), dentre os métodos citados, a cauterização é a primeira escolha, uma vez que é mais eficaz, principalmente em sangramentos severos. Todavia, a cauterização da epistaxe tem algumas desvantagens podendo formar crostas, causar rinorréia (corrimento excessivo de muco nasal), queimaduras no lábio ou na pele do vestíbulo, e pode levar à ulceração e perfuração do septo. Dessa forma, o objetivo deste estudo é propor uma alternativa rápida para tratar casos de epistaxe, que promova o mínimo de efeito colateral, dor e lesão ao paciente. Assim, para controlar a epistaxe, propõe-se um tampão produzido de um tecido nãotecido eletrofiado de poli(L-ácido láctico) e poliacetato de vinila funcionalizado com um agente anti-hemorrágico (ácido tranexâmico) que deverá ser utilizado para tamponar a fossa nasal durante epistaxe.

Costa et. al. (2012) e Claudiano (2013) relatam que a eletrofiação é um processo em que fenômenos físicos e químicos agem mutuamente. Conhecido e estudado desde a década de 1930, com o objetivo de se produzir fibras poliméricas em escala nano, que se aperfeiçoou mais tarde com a vinda de novos estudos sobre nanotecnologia e produção de nanofibras e nanofios de vários polímeros. A técnica de eletrofiação baseia-se em um campo elétrico, onde forças eletrostáticas excedem as forças interfaciais. Inicialmente, a solução é condicionada 
pela sua tensão superficial na forma de uma gota na saída do capilar, , e então na saída do mesmo, ocorre um estiramento contínuo da nanofibra em direção à placa coletora (superfície metálica revestida), onde somente o soluto é depositado (o solvente evapora quando a gotícula se forma na saída do capilar, uma vez que não é desejado no nãotecido), (Guerrini, 2006; Claudian, 2013). Uma série de aplicações pode ser obtida através da eletrofiação, já que este minucioso processo tem a capacidade de alterar propriedades do material, e entre as principais se encontra a área médica, como por exemplo a produção de nãotecidos para liberação controlada de fármacos. O desenvolvimento de biomateriais com características que ajudem na recuperação de uma doença ou de uma urgência hospitalar, como nos casos de epistaxe, é um desafio nas pesquisas que envolvem áreas como medicina e engenharia. Dentre os biomateriais, os polímeros bioabsorvíveis são considerados uma boa alternativa para novos avanços de aplicações biomédicas, de acordo com Lasprilla (2011).

Segundo afirmações de Lasprilla (2011), o poli(ácido láctico) (PLA) é um dos principais biopolímeros biodegradáveis e bioabsorvíveis, possui baixa toxicidade, boa biocompatibilidade e boas propriedades mecânicas. O ácido láctico é oriundo de plantas, animais e microorganismos, e também da fermentação de açúcares obtidos de recursos como cana-de-açúcar e beterraba. A partir dele é possível alterar e/ou ampliar propriedades químicas e mecânicas, deixando-os adequados para o uso em pesquisas. Dentre os polímeros mais buscados para estudos na área biomédica encontra-se o poli (L-ácido láctico) (PLLA).

O trabalho de Inhoato (2013) mostra que o PLLA é um poliéster hidrofóbico, biodegradável, de ótima resistência mecânica, plasticidade térmica, e reabsorvível. Recebe alta atenção pelo fato de ter tido aprovação pelo Food and Drug Administration (FDA) para utilização como sistemas de liberação de fármacos.

Com isto, o objetivo deste estudo é desenvolver um tampão nasal a partir de um nãotecido de biopolímero eletrofiado, com adição de um fármaco anti-hemorrágico, para tratar casos de epistaxe. Este nãotecido será utilizado na forma de tampão nasal e terá como finalidade estancar o sangue, evitando, muitas vezes, que o médico necessite cauterizar o ponto de sangramento, oferecendo ao paciente o mínimo de dor e desconforto, e maior rapidez no tratamento e recuperação.

\section{Materiais e Métodos}

Os experimentos laboratoriais foram realizados no Laboratório de Transferência de Massa do Departamento de Engenharia Química e Engenharia de Alimentos da Universidade Federal de Santa Catarina.

\subsection{Materiais}

Neste estudo, o polímero utilizado foi o Poli (L-ácido láctico) fornecido pela PURAC. Os solventes utilizados foram o clorofórmio, com grau de pureza de $99,8 \%$ fornecido pela VETEC e dimetilformamida, grau de pureza $99 \%$ fornecido por SIGMA-ALDRICH. O fármaco anti-hemorrágico utilizado foi o Transamin, adquirido em farmácia. Todos os materiais foram usados sem tratamentos prévios.

\subsection{Métodos}




\subsubsection{Preparo da solução a ser eletrofiada}

O PLLA foi solubilizado em clorofórmio sob agitação magnética constante em temperatura ambiente por $24 \mathrm{~h}$. A solução teve concentração de $1,2 \%(\mathrm{~m} / \mathrm{m})$. Após solubilização completa do polímero, adicionado-se $10 \%$ (v/v) de dimetilformamida.

\subsubsection{Processo de eletrofiação do nãotecido}

O polímero foi eletrofiado mediante as seguintes condições: $12 \mathrm{~cm}$ de distância entre o capilar e a placa coletora, voltagem de $23 \mathrm{kV}$, vazão de infusão do polímero de $2 \mathrm{ml} / \mathrm{h}$, a placa coletora rotatória girando a $33 \mathrm{rpm}$. A umidade relativa do ar foi de $56 \%$ e temperatura de 23 ${ }^{\circ} \mathrm{C}$.

\subsubsection{Incorporação do anti-hemorrágico}

Durante eletrofiação, o agente anti-hemorrágico foi pulverizado por electrospraying, através de um capilar adjacente, sendo depositado juntamente com o polímero na placa coletora.

\subsubsection{Análise de Microscopia eletrônica de varredura (MEV)}

A análise morfológica dos nãotecidos produzidos foi realizada por microscopia eletrônica de varredura em um microscópio eletrônico da marca JEOL, modelo JSM-6390LV.

\section{Resultados e Discussão}

Neste trabalho, o poli(L-ácido lático) foi utilizado como matéria-prima para produção de um nãotecido eletrofiado com adição de um anti-hemorrágico para produção de tampões nasais destinados ao tratamento de epistaxe. Os nãotecidos eletrofiados foram analisados por microscopia eletrônica de varredura e as imagens são mostradas a seguir.

Figura 1 - MEV do nãotecido de PLLA com ampliação de 2000x: a) sem aplicação do antihemorrágico; b) com aplicação do anti-hemorrágico
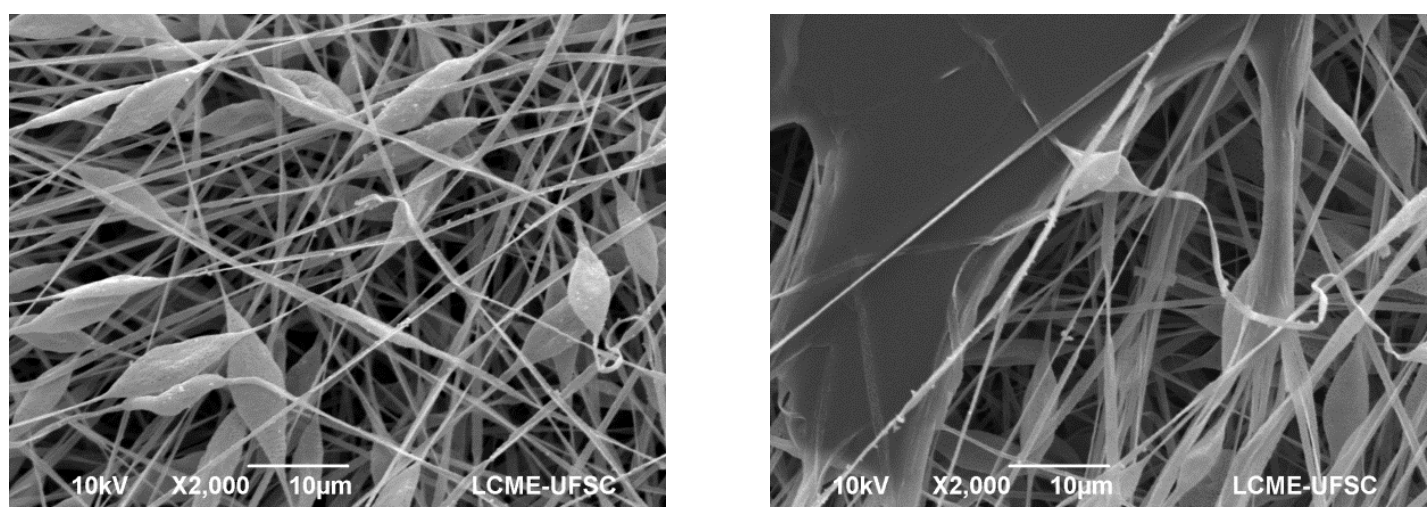

A Figura 1(a) apresenta a morfologia de um nãotecido produzido com PLLA sem a incorporação do aditivo anti-hemorrágico. A imagem mostra fibras de PLLA regulares com diâmetros submicrométricos e baixa porosidade, porém, com presença de beads, gotas de 
polímero não estirado durante eletrofiação. Os beads são geralmente indesejáveis em um nãotecido e podem ter ocorrido devido às condições de trabalho definidas para o processo de eletrofiação. É provável que a distância estabelecida entre a agulha e o coletor tenha sido insuficiente para o estiramento adequado das fibras, ou que a vazão de alimentação tenha sido muito elevada, infundindo muito material em um curto espaço de tempo, impossibilitando o estiramento desejado. Assim, faz-se necessário um estudo mais minucioso das condições ótimas de operação para solucionar este efeito indesejado nos nãotecidos.

A Figura 1(b) apresenta a análise de imagem do nãotecido com adição do antihomorrágico, que se encontra espalhado entre as camadas de fibra, principalmente na camada externa, de forma aleatória. As gotas internas não foram detectadas, pois a malha de fibras encontra-se muito densa e fechada, dificultando o acesso às camadas mais internas de fibras.

\section{Conclusão}

Este trabalho desenvolvido para produção de um nãotecido com a aplicação de um agente coagulante para tratar epistaxe representa uma alternativa aos métodos propostos até agora. O estudo mostrou que é possível eletrofiar o polímero e aplicar o agente coagulante simultaneamente via electrospraying, produzindo fibras com diâmetros regulares e baixa porosidade. Porém, estudos focados nas condições de trabalho da eletrofiação serão necessários para evitar a presença de beads encontrados no nãotecido.

\section{REFERÊNCIAS}

ANIKKO, M.; BERNAL-SPREKELSEN, M.; BONKOWSKY, V.; BRADLEY P.; LURATO S. Otorhinolaryngology, Head and Neck Surgery. Ed. Springer, 738 p, 2010.

BALBANI, A. P. S.; FORMIGONI, G. G. S.; BUTUGAN, O. Tratamento da Epistaxe. Disciplina de Otorrinolaringologia da Faculdade de Medicina da Universidade de São Paulo, São Paulo, SP, 1999.

CLAUDIANO, G. V.; MORAES, M. A.; BEPPU, M. M.; D’ÁVILA, A. Eletrofiação a partir de soluções de fibroína de seda. 12 Congresso Brasileiro de Polímeros, 2013.

COSTA, R. G. F.; OLIVEIRA, J. E.; PAULA, G. F.; PICCIANI, P. H. S.; MEDEIROS, E. S.; RIBEIRO, C.; MATTOSO, L. H. C. Eletrofiação de polímeros em solução. Parte I: Fundamentação teórica. Polímeros, V.22, N. 2, p. 170-177, Universidade Federal de São Carlos, São Carlos, SP, 2012.

FAISTAUER, M.; FAISTAUER, A.; GROSSI, R. S.; ROITHMANN, R. Desfecho clínico de pacientes tratados por epistaxe com tamponamento nasal após a alta hospitalar. Brazilian Journal of Otorhinolaryngology. V. 75, n. 6, São Paulo, 2009.

GUERRINI, L. M.; BRANCIFORTI, M. C.; BRETAS, E. S.; OLIVEIRA, M. P. Eletrofiação do Poli(álcool vinílico) via solução aquosa. Polímeros: Ciência e Tecnologia, vol. 16, n.4, p. 286-293, Universidade Federal de São Carlos, São Carlos, SP, 2006.

INHOATO, L. A. Influência de parâmetros experimentais na síntese de poli (L-ácido lático). Universidade Tecnológica Federal do Paraná, Campo Mourão, 2013.

LASPRILlA, A. J. R. Síntese do Poli-Ácido Láctico a partir do ácido láctico para aplicação biomédica. Unicamp, Campinas, SP, 2011.

MEIRELLES, R. C.; SÁ, L. C. B.; ALMEIDA, G. Abordagem atual das hemorragias nasais. Vol. 11, N. 3, Otorrinolaringologia geriátrica, 2012. 
VITAL, B. R.; MACIEL, A. S.; LUCIA, R. M. D. Qualidade de juntas coladas com lâminas de madeira oriundas de três regiões do tronco de Eucalyptus grandis, Eucalyptus saligna e Pinus elliotii. Rev Árvore. Vol. 30, n. 4. Viçosa, 2006. 